\title{
Smartphone-Based Color Measurement of Tooth Shade Guide in Clinical Lighting Conditions
}

\author{
Agnieszka Radziun, \\ Rafał Doniec, Szymon Sieciński, \\ Natalia Piaseczna, Konrad Duraj, \\ Ewaryst Tkacz \\ Silesian University of Technology \\ Faculty of Biomedical Engineering \\ Department of Biosensors \\ and Processing of Biomedical Signals \\ F. D. Roosevelta 40, \\ 41-800 Zabrze, Poland \\ Email: agnieszkaaradziun@gmail.com, \\ rafal.doniec@polsl.pl \\ szymon.siecinski@polsl.pl \\ natalia.piaseczna@polsl.pl \\ kondrad.duraj@polsl.pl,etkacz@polsl.pl
}

\author{
Katarzyna Mocny-Pachońska, \\ Marta Tanasiewicz \\ Department of Conservative \\ Dentistry with Endodontics,
}

Faculty of Medical Sciences in Zabrze,

Medical University of Silesia

Plac Akademicki 17

41-902 Bytom, Poland

Email: kpachonska@sum.edu.pl

martatanasiewicz@sum.edu.pl

\author{
Marta Cieślik-Wegemund \\ Department of Periodontal \\ and Oral Mucosa Diseases, \\ Faculty of Medical Sciences in Zabrze, \\ Medical University of Silesia, \\ Plac Traugutta 2 \\ 41-800 Zabrze, Poland \\ Email: martawegemund@gmail.com
}

\begin{abstract}
Caries is a common disease of hard tissues of teeth which results in dental cavities, which are usually replaced by dental fillings. Matching the color of a dental filling is usually a subjective assessment. In this study, we conducted a color analysis of GC Gradia Direct shade guide in the lighting conditions of the dental office. Color measurement was performed using Color Grab mobile app and the results were acquired as values of RGB (red, green, blue) and HSV (hue, saturation, color value) values. The results indicate the possibility of identifying each shade of tooth by the most prominent changes in RGB and/or HSV components.
\end{abstract}

\section{INTRODUCTION}

C ARIES is a common disease of hard tissues of the teeth caused by bacteria, which leads to the demineralization and proteolytic decay [1], [2]. The damage of tooth hard tissue associated with caries is defined as cavity [3]. Due to the fact that the damaged structure of the tooth does not regenerate, it must be replaced by a filling. Restorative materials include gold, dental amalgam, composite, and porcelain resins [4].

One of the composite materials used for fillings to match the color to the patient's teeth is GC Gradia Direct dental composite material (GC Europe NV, Leuven, Belgium), which recreates the optical properties of natural teeth and is available in several versions that differ in color scale [5].

Color as an optical value significantly affects the appearance of the tooth [6], [7]. The color depends not only on the shade, but also on the saturation, brightness, and tooth morphology [7]. The perception of tooth color depends on the way it reflects the light [6], [8].

This work was not supported by any organization.
In most cases, a dentist matches the filling color by the subjective assessment based on comparison of the shade of tooth with the shade guide [6], [7]. To reduce the effects of metamerism, a standardized light source should be used [6]. Three most common light sources in dentistry are natural, fluorescent, and incandescent [9]. Measurement of color of a wide range of materials and substrates has been performed by spectrophotometers and colorimeters for several years [10], also in dentistry [11], [12].

Spectrophotometers measure the amount of light absorbed by the sample using the Lambert Beer law. They consist of their own light source, monochromator, a sample, and photodetector [10]. Due to the technological progress and the decreasing price of devices, the use of spectrophotometers in dentistry has become a viable alternative to visual matching [13], [14]. Another method for tooth color analysis is using dental microscopes [2].

Due to the increasing capabilities of smartphones, there have been proposed several applications, including color measurements [15], [16]. For instance, Kim et al. [15] applied smartphones to perform colorimetric $\mathrm{pH}$ measurement. Hasan et al. proposed a method for measuring hemoglobin level with smartphones [16].

The purpose of the study was to perform the color analysis of a commercially available shade guide (GC Gradia Direct) with mobile apps in the lighting conditions of the dental office and analyze the influence of light intensity and energy (visible light or ultraviolet light) on the color components of available shades in RGB and HSV color spaces, which may be useful in distinguishing the available shades. 


\section{MATERIAL AND MEthods}

\section{A. Material}

Our study involved only a commercially available tooth shade guide (GC Gradia Direct produced by GC Europe NV, Leuven, Belgium) which contains the shades of teeth in the form of a palette with wedge-shaped color samples (see Fig. 1). The order of the colors in the shade guide is as follows: BW, A1, A2, A3, A3.5, A4, B2, B3, C3, CV, CVD, WT, DT, CT, NT and GT [5, pp. 6-7].

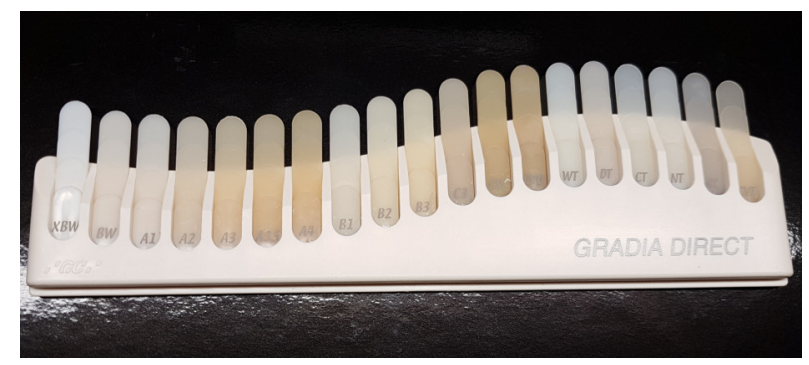

Fig. 1. GC Gradia Direct shade guide (own source).

\section{B. Experiments}

The study was conducted on a commercially available tooth shade guide (GC Gradia Direct) in typical lighting conditions of a dental office (visible light and ultraviolet (UV) light additionally lit by daylight through the windows). We used a smartphone with a camera, its own light source, and two mobile apps for Android: Lux Light Meter (Marcel Waldau Webdesign) [17] and Color Grab (Loomatix) available at the Google Play Store. Color Grab app performs real-time color callibration [18], whereas Lux Light Meter has its own callibration mechanism [17].

The first app allowed the measurement of light intensity $E$ in lux (lx) at the test site, and the second app measured RGB (red, green, blue) and HSV (hue, saturation, color intensity value) component values in the shade guide. RGB and HSV values were taken under visible light for the following illuminance values: $130 \mathrm{~lx}, 165 \mathrm{~lx}$, and $201 \mathrm{~lx}$, and also under the LE-900 ultraviolet lamp with the power input of $90 \mathrm{~W}$; output voltage and current of $12 \mathrm{~V} \mathrm{DC}, 1 \mathrm{~A}$; input voltage of 100-240 V AC, 50/60 Hz, and illuminance of $50 \mathrm{~lx}$.

RGB values were expressed in the range of $0-255$. Hue values were expressed in the range of $0-360^{\circ}$, saturation, and color intensity values were expressed in percents $(0-100 \%)$. RGB values were converted to HSV values based on the transformation algorithm by Smith in [19].

\section{Analysis of results}

The obtained color components in RGB and HSV color spaces were analyzed visually to indicate the most prominent components. Then, the differences between the shades coded as shown in table III were further analyzed quantitatively by calculating the percentage of unique values of components, Spearman's rank correlation, and Pearson's linear correlation coefficient for the shades in UV and visible light to evaluate the monotonicity and linearity of the changes in color components between the shades which were assigned to an ordinal scale [20], [21].

For the shades in visible light, the Kruskal-Wallis test was additionally conducted to evaluate the significance of changes of the most prominent components in different light intensities. The quantitative analyses were conducted with MATLAB R2020b (MathWorks, Inc., Natick, MA, USA) and Pandas Profiling version 2.11.0 running under Python 3.9.

\section{RESULTS}

During the study, not all locations in the dental office had the same light intensity because two types of lamps were used and some places were additionally lit by sunlight due to the location of the window. The results of color measurements under visible light are presented in subsection III-A and the results of color measurement under ultraviolet light are presented in subsection III-B.

\section{A. Visible light}

The RGB and HSV values of shades in the GC Gradia Direct shade guide measured under visible light are shown in Tab. I and Tab. II.

Each shade in the shade guide has its own value. RGB values are significantly influenced by the changes of light intensity, as observed in table I.

The HSV values of the same shades in the GC Gradia Direct in visible light (see table II) have very similar color intensity value for $E=130 \mathrm{~lx}$ and $E=165 \mathrm{~lx}$. For $E=201 \mathrm{~lx}$, the $\mathrm{V}$ values of the analyzed shades are more significant and may help distinguish each shade. More prominent feature of the shades are hue and saturation for all analyzed light intensities in visible light.

The relationships of values of color components with the shades for all considered illuminances were also evaluated quantitatively by calculating the Spearman's rank correlation and Pearson's linear correlation coefficients (see table IV), and Kruskal-Wallis test after assigning numbers from 0 to 15 for the shades (see table III). The percentage of distinct component values are shown in table $\mathrm{V}$.

The $r$ values shown in Tab. IV show that the relationship between color components (blue in RGB, hue and saturation in HSV color spaces) and tooth shade is not monotonic and/or linear, except for the hue component in $130 \mathrm{~lx}(r=0.556, p<$ $0.05)$, which is monotonic. However, the differences between the blue component, hue, and saturation for each shade as coded in Tab. III in visible light are significant in KruskalWallis test for $p<0.05$ (see figures 2, 3, and 4 and tables VI, VII, and VIII). In Kruskal-Wallis test results, SS is the sum of squares due to each source, $\mathrm{df}$ is the number of degrees of freedom associated with each source, MS are the mean squares for each source, and $\chi^{2}$ is the test statistic. 
TABLE I

RGB values of GC GRadia Direct SHADES IN VISIBLE Light.

\begin{tabular}{|c|c|c|c|c|c|c|c|c|c|c|c|c|c|c|c|c|c|}
\hline $\bar{E}$ & hade & $\bar{W}$ & 1 & 2 & 3 & 3.5 & A4 & B2 & B3 & $\mathrm{C} 3$ & $\mathrm{~V}$ & VD & VT & DT & $\mathrm{CT}$ & NT & GT \\
\hline \multirow{3}{*}{$\overrightarrow{0}$} & Red & & & 253 & 253 & 251 & 254 & 254 & 254 & 251 & & & 254 & 254 & 52 & 253 & 240 \\
\hline & Sre & & & 252 & 247 & 48 & 246 & 54 & 254 & 249 & 248 & & 54 & 254 & 54 & & 241 \\
\hline & Blue & & 241 & 237 & 227 & 225 & 220 & 243 & 238 & 233 & 226 & & 252 & 247 & 248 & 254 & 233 \\
\hline \multirow{3}{*}{$\tilde{z}$} & Red & 54 & 254 & 250 & 254 & 255 & 254 & 253 & 252 & 245 & 248 & 24 & 254 & 252 & 250 & 251 & 242 \\
\hline & Green & 54 & 254 & 253 & 250 & 252 & 246 & 252 & 248 & 239 & 24 & 23 & 254 & 254 & 251 & 252 & 244 \\
\hline & Blue & 250 & 249 & 244 & 226 & 230 & 217 & 235 & 220 & 218 & 21 & 21 & 242 & 252 & 242 & 247 & 240 \\
\hline \multirow{3}{*}{$\underline{\Xi}$} & Red & 254 & 248 & 245 & 243 & 211 & 222 & 229 & 230 & 254 & 251 & 24 & 233 & 241 & 249 & 250 & 228 \\
\hline & Green & 254 & 252 & 248 & 233 & 206 & 208 & 230 & 219 & 253 & 250 & 20 & 240 & 241 & 250 & 251 & 236 \\
\hline & Blue & 246 & 239 & 225 & 200 & 174 & 168 & 203 & 180 & 235 & 230 & 20 & 225 & 220 & 234 & 236 & 229 \\
\hline
\end{tabular}

TABLE II

HSV VALUES OF GC GRADIA DiRECT SHADES IN VISIBLE LIGHT

\begin{tabular}{|c|c|c|c|c|c|c|c|c|c|c|c|c|c|c|c|c|c|}
\hline E & Shade & BW & A1 & A2 & A3 & A3.5 & A4 & B2 & B3 & C3 & $\mathrm{CV}$ & CVD & WT & DT & CT & NT & GT \\
\hline \multirow{3}{*}{$\begin{array}{l}\underline{x} \\
\stackrel{g}{g}\end{array}$} & $\mathrm{H}\left[^{\circ}\right]$ & 60 & 55 & 56 & 46 & 48 & 46 & 60 & 60 & 53 & 49 & 50 & 60 & 60 & 80 & 180 & 67 \\
\hline & $\mathrm{S}[\%]$ & 2 & 5 & 6 & 10 & 11 & 13 & 4 & 6 & 7 & 11 & 11 & 1 & 3 & 2 & 0 & 3 \\
\hline & $\mathrm{V}[\%]$ & 100 & 99.6 & 99.2 & 99.21 & 99.6 & 99.6 & 99.6 & 99.6 & 8.43 & 99.21 & 99.21 & 99.6 & 99.6 & 99.6 & 99.6 & 94.5 \\
\hline \multirow{3}{*}{$\underline{a}$} & $\mathrm{H}\left[{ }^{\circ}\right]$ & 60 & 60 & 120.7 & 51.42 & 52.8 & 47.02 & 56.67 & 52.5 & 46.67 & 48.33 & 46.87 & 60 & 120.4 & 120.2 & 120.2 & 120.4 \\
\hline & $\mathrm{S}[\%]$ & 1.57 & 1.96 & 3.55 & 11.02 & 9.8 & 14.56 & 7.11 & 12.69 & 11.02 & 14.51 & 13.11 & 4.72 & 0.78 & 3.58 & 1.98 & 1.63 \\
\hline & $\mathrm{V}[\%]$ & 99.6 & 99.6 & 99.21 & 99.6 & 100 & 99.6 & 99.21 & 98.82 & 96.07 & 97.25 & 95.68 & 99.6 & 99.6 & 98.43 & 98.82 & 95.68 \\
\hline \multirow{3}{*}{$\begin{array}{l}\underline{x} \\
\vec{\sim}\end{array}$} & $\mathrm{H}\left[{ }^{\circ}\right]$ & 60 & 78 & 68 & 46 & 52 & 44 & 62 & 47 & 57 & 57 & 0 & 88 & 60 & 63.75 & 64 & 127.5 \\
\hline & $\mathrm{S}[\%]$ & 3 & 5 & 9 & 18 & 17.53 & 24.32 & 11.73 & 21.73 & 7.48 & 8.36 & 13.99 & 6.25 & 8.71 & 6.4 & 5.97 & 3.38 \\
\hline & $\mathrm{V}[\%]$ & 99.6 & 98.82 & 97.25 & 95.29 & 82.74 & 87.05 & 90.19 & 90.19 & 99.6 & 98.43 & 95.29 & 94.11 & 94.50 & 98.03 & 98.43 & 92.54 \\
\hline
\end{tabular}

TABLE III

CODE ASSIGNMENTS FOR AVAILABLE TOOTH SHADES.

\begin{tabular}{|c|c|c|c|c|c|c|c|c|c|c|c|c|c|c|c|c|}
\hline Shade & BW & A1 & A2 & A3 & A3.5 & A4 & B2 & B3 & C3 & CV & CVD & WT & DT & CT & NT & GT \\
\hline Code & 0 & 1 & 2 & 3 & 4 & 5 & 6 & 7 & 8 & 9 & 10 & 11 & 12 & 13 & 14 & 15 \\
\hline
\end{tabular}

TABLE IV

SPEARMAN'S RANK CORRELATION AND PEARSON'S LINEAR CORRELATION BETWEEN THE SHADES IN VISIBLE LIGHT.

\begin{tabular}{|c||c|c||c|c||c|c|}
\hline \multicolumn{7}{|c|}{ Spearman's rank correlation } \\
\hline Illuminance & \multicolumn{2}{|c|}{$130 \mathrm{~lx}$} & \multicolumn{2}{c|}{$165 \mathrm{~lx}$} & \multicolumn{2}{c|}{$201 \mathrm{~lx}$} \\
\hline Component & $r$ & $p$ & $r$ & $p$ & $r$ & $p$ \\
\hline Blue & 0.219 & 0.415 & -0.049 & 0.858 & 0.196 & 0.466 \\
Hue & 0.556 & 0.025 & 0.218 & 0.417 & 0.253 & 0.344 \\
Saturation & -0.380 & 0.147 & -0.100 & 0.713 & -0.265 & 0.321 \\
\hline \multicolumn{7}{|c|}{ Pearson's linear correlation } \\
\hline Blue & 0.235 & 0.382 & -0.012 & 0.965 & 0.090 & 0.741 \\
Hue & 0.478 & 0.062 & 0.499 & 0.049 & 0.252 & 0.347 \\
Saturation & -0.364 & -0.153 & -0.153 & 0.713 & -0.227 & 0.398 \\
\hline
\end{tabular}

\section{B. UV light}

Because the changes of the measured RGB components of the shades were the most prominent for B component, the color measurement was retaken under ultraviolet light. The RGB and HSV values are shown in table IX.

In RGB color space, the most prominent features of the analyzed shades are green component values, whereas the most prominent features of the shades in HSV color model
TABLE V

Percentages of UniQue VAlues of COLOR COMPONENTS.

\begin{tabular}{|c|c|c|c|}
\hline \multicolumn{4}{|c|}{ Visible light } \\
\hline Illuminance & $130 \mathrm{~lx}$ & $165 \mathrm{~lx}$ & $201 \mathrm{~lx}$ \\
\hline Component & Uniqueness [\%] & Uniqueness [\%] & Uniqueness [\%] \\
\hline Blue & 93.8 & 87.5 & 93.8 \\
Hue & 68.8 & 87.5 & 87.5 \\
Saturation & 68.8 & 100 & 100 \\
\hline \multicolumn{3}{|c|}{ Ultraviolet light } \\
\hline Illuminance & \multicolumn{3}{|c|}{ Uniqueness [\%] } \\
\hline Component & \multicolumn{3}{|c|}{100} \\
\hline Green & \multicolumn{3}{|c|}{87.5} \\
Hue & \multicolumn{3}{|c|}{} \\
\hline
\end{tabular}

TABLE VI

RESULTS OF KRUSKAL-WALLIS TEST FOR BLUE.

\begin{tabular}{|c|c|c|c|c|c|}
\hline Source & SS & df & MS & $\chi^{2}$ & $p$ \\
\hline Columns & 5600 & 15 & 373.333 & 28.6 & 0.0181 \\
Error & 3603.5 & 32 & 112.609 & & \\
Total & 9203.5 & 47 & & & \\
\hline
\end{tabular}

are hue, for shades BW, A1 and NT, and saturation with the color intensity value for A4 shade. These observations were 


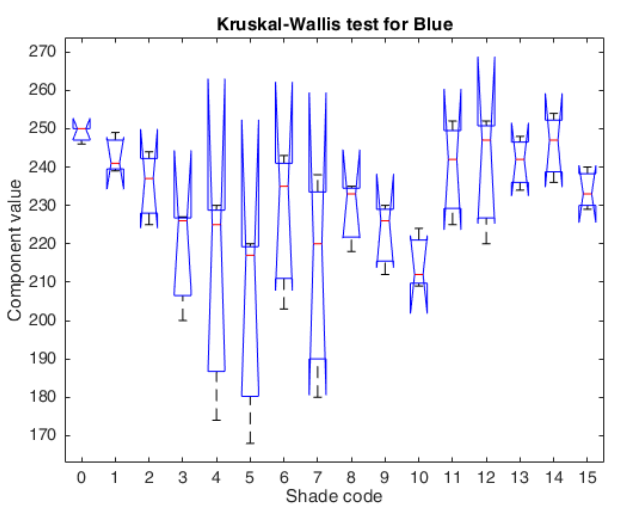

Fig. 2. The boxplot for blue component between the analyzed shades.

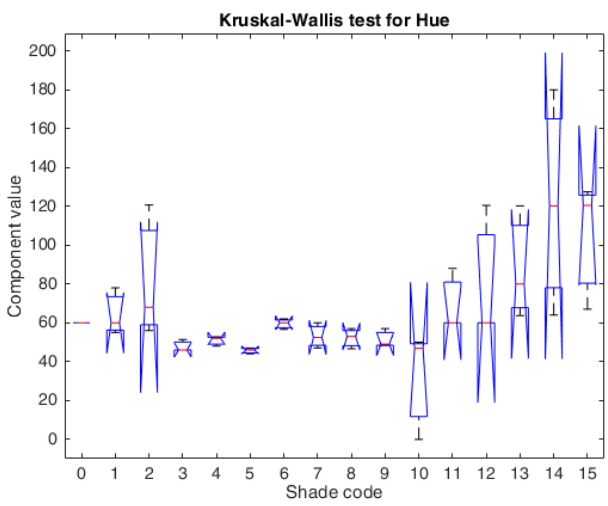

Fig. 3. The boxplot for hue between the analyzed shades.

TABLE VII

RESULTS OF KRUSKAL-WALLIS TEST FOR HUE.

\begin{tabular}{|c|c|c|c|c|c|}
\hline Source & SS & df & MS & $\chi^{2}$ & $p$ \\
\hline Columns & 7431.17 & 15 & 495.411 & 38.27 & 0.008 \\
Error & 1695.83 & 32 & 52.995 & & \\
Total & 9127 & 47 & & & \\
\hline
\end{tabular}

TABLE VIII

RESULTS OF KRUSKAL-WALLIS TEST FOR SATURATION.

\begin{tabular}{|c|c|c|c|c|c|}
\hline Source & SS & df & MS & $\chi^{2}$ & $p$ \\
\hline Columns & 6971 & 15 & 464.733 & 35.59 & 0.0002 \\
Error & 2235.5 & 32 & 69.859 & & \\
Total & 9206.5 & 47 & & & \\
\hline
\end{tabular}

confirmed by calculating the uniqueness of component values expressed as the percentage of the unique values in table $\mathrm{V}$.

The $r$ values shown in table $\mathrm{X}$ show that the association between analyzed variables (green in RGB, hue in HSV, color spaces, and tooth shades) is not monotonic and/or linear for $p<0.05$.

\section{DISCUSSION}

We measured the colors of the GC Gradia Shade Guide in a dental office using a smartphone. Measuring color changes

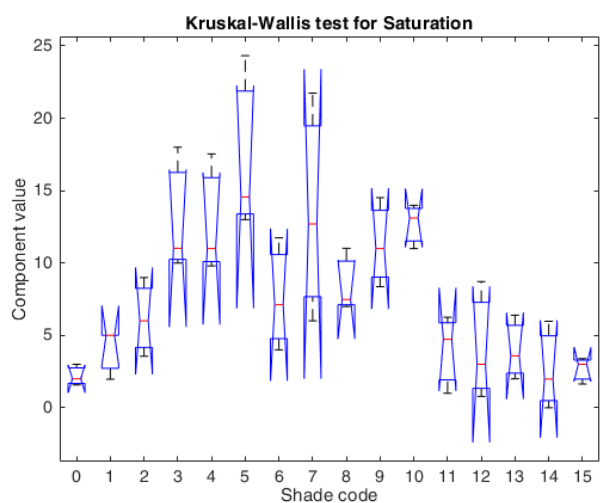

Fig. 4. The boxplot for saturation between the analyzed shades.

using a smartphone is a challenging task due to the light conditions and non-linear relationship between the light intensity and the RGB of the shade [22]. Aforementioned statement also applies to HSV and CMYK color spaces. These observations were confirmed quantitatively by the Spearman's rank correlation and Pearson's linear correlation coefficients presented in tables IV and X.

The values of components in RGB, HSV and CMYK color spaces depend on the power of the light source, the influence of the daylight, position of the light source, and the distance between the camera and the measured object.

The most prominent features of shades under visible light are the value of blue component in RGB color space, hue, and saturation in HSV color space. These findings were also supported by calculating the uniqueness of values of color components and the results of Kruskal-Wallis tests.

The most prominent feature in ultraviolet light was the green component in RGB model, and hue component in HSV model. That finding was confirmed by calculating the uniqueness of color component values shown in table V. That means that each shade of tooth may be identified by the most prominent changes in RGB and/or HSV components, namely blue, hue, and saturation in visible light, and green and hue in ultraviolet light.

The findings of our study may help develop a model of teeth shades to improve dental care by optimizing the process of color matching in the preparation of dental fillings despite using other approaches to spectrophotometry than described in the literature [11], [12].

The most significant limitation of our study is no evaluation of the influence of daylight on the measured color components and the fact that using smartphone apps in illuminance measurement is not recommended due to the discepancies in measured values between the devices and various apps [23], [24]. However, smartphone cameras are suitable for color measurements [15], [16].

In future studies, we consider other shade guides, more light intensities, and minimizing the influence of daylight and non-uniform light distribution on color measurement. We 
TABLE IX

RGB AND HSV VALUES OF GC GRADIA DIRECT SHADES IN UV LIGHT AND E $=50 \mathrm{LX}$.

\begin{tabular}{|c|c|c|c|c|c|c|c|c|c|c|c|c|c|c|c|c|}
\hline Shade & BW & A1 & A2 & A3 & A3.5 & A4 & B2 & B3 & C3 & CV & CVD & WT & DT & CT & NT & GT \\
\hline Red & 12 & 36 & 0 & 0 & 0 & 0 & 0 & 0 & 0 & 0 & 0 & 0 & 0 & 0 & 7 & 0 \\
\hline Green & 214 & 204 & 175 & 133 & 105 & 66 & 189 & 179 & 120 & 56 & 25 & 13 & 185 & 208 & 199 & 128 \\
\hline Blue & 255 & 255 & 255 & 255 & 255 & 255 & 255 & 255 & 255 & 255 & 255 & 217 & 255 & 255 & 255 & 255 \\
\hline${\text { H }\left[{ }^{\circ}\right]}^{190}$ & 194 & 199 & 209 & 215 & 224 & 196 & 198 & 212 & 227 & 234 & 236 & 196 & 191 & 194 & 210 \\
\hline S [\%] & 95.29 & 85.88 & 100 & 100 & 100 & 100 & 100 & 100 & 100 & 100 & 100 & 100 & 100 & 100 & 97.25 & 100 \\
\hline V [\%] & 100 & 100 & 100 & 100 & 100 & 100 & 100 & 100 & 100 & 100 & 100 & 85,09 & 100 & 100 & 100 & 100 \\
\hline
\end{tabular}

TABLE X

SPEARMAN'S RANK CORRELATION AND PEARSON'S LINEAR CORRELATION BETWEEN THE SHADES IN ULTRAVIOLET LIGHT.

\begin{tabular}{|c|c|c||c|c|}
\hline & \multicolumn{2}{|c||}{ Spearman's } & \multicolumn{2}{c|}{ Pearson's } \\
\hline Component & $r$ & $p$ & $r$ & $p$ \\
\hline Green & -0.182 & 0.415 & -0.190 & 0.482 \\
Hue & -0.155 & 0.567 & -0.180 & 0.505 \\
Magenta & 0.182 & 0.498 & 0.189 & 0.484 \\
\hline
\end{tabular}

also consider the development of a mobile app for tooth color measurements which may be used to lower the cost of matching optimal shades of teeth in comparison with buying a commecially available dental spectrophotometer, especially in whitening the color of teeth or filling the cavities with dental fillings.

\section{REFERENCES}

[1] H. Silk, "Diseases of the mouth," Primary Care: Clinics in Office Practice, vol. 41, no. 1, pp. 75 - 90, 2014. doi: 10.1016/j.pop.2013.10.011 Primary Care ENT

[2] O. Osadcha, A. Trzcionka, K. Pachońska, and M. Pachoński, "Detection of dental filling using pixels color recognition," in Information and Software Technologies, R. Damaševičius and G. Vasiljevienè, Eds. Cham: Springer International Publishing, 2018. doi: 10.1007/978-3-31999972-2_28. ISBN 978-3-319-99972-2 pp. 347-356.

[3] L. Bjørndal, S. Simon, P. L. Tomson, and H. F. Duncan, "Management of deep caries and the exposed pulp," International Endodontic Journal, vol. 52, no. 7, pp. 949-973, 2019. doi: https://doi.org/10.1111/iej.13128

[4] D. Bratthall, P. E. Petersen, J. R. Stjernswärd, and L. J. Brown, "Ora and craniofacial diseases and disorders," in Disease Control Priorities in Developing Countries, 2nd ed., D. T. Jamison, J. G. Joel G Breman, A. R. Measham, G. Alleyne, M. Claeson, D. B. Evans, P. Jha, A. M. Mills, and P. Musgrove, Eds. World Bank, Washington (DC), 2006, ch. 38, pp. 723-736. ISBN 0821361791. [Online]. Available: https://www.ncbi.nlm.nih.gov/books/NBK11725/

[5] "GC Gradia Direct light-cured composite restorative clinical guide," accessed 21 March 2021. [Online]. Available: https://cdn.gceurope.com/v1/PID/gradiadirect/manual/MAN_ Gradia_Direct_Clinical_Guide_en.pdf

[6] A. Watts and M. Addy, "Tooth discolouration and staining: a review of the literature," British Dental Journal, vol. 190, no. 6, pp. 309-316, March 2001. doi: https://dx.doi.org/10.1038/sj.bdj.4800959

[7] A. Joiner, "Tooth colour: a review of the literature," Journal of Dentistry, vol. 32, pp. 3-12, 2004. doi: https://doi.org/10.1016/j.jdent.2003.10.013 Advances in tooth whitening: A new, simple and effective solution.

[8] K. W. Aschheim and B. A. Singer, "Fundamentals of esthetics and smile analysis," in Esthetic Dentistry. Elsevier, 2015, pp. 38-54.

[9] L. Miller, "Organizing color in dentistry," The Journal of the American Dental Association, vol. 115, pp. 26E-40E, Dec. 1987. doi: https://dx.doi.org/10.14219/jada.archive.1987.0315
[10] T. A. Germer, J. C. Zwinkels, and B. K. Tsai, "Chapter 1 - introduction," in Spectrophotometry, ser. Experimental Methods in the Physical Sciences, T. A. Germer, J. C. Zwinkels, and B. K. Tsai, Eds. Academic Press, 2014, vol. 46, pp. 1-9.

[11] C. Igiel, M. Weyrauch, S. Wentaschek, H. Scheller, and K. M. Lehmann, "Dental color matching: A comparison between visual and instrumental methods," Dental Materials Journal, vol. 35, no. 1, pp. 63-69, 2016. doi: https://dx.doi.org/10.4012/dmj.2015-006

[12] J. C. Ragain, "A review of color science in dentistry: Colorimetry and color space," Journal of Dentistry, Oral Disorders \& Therapy, vol. 4, no. 1, pp. 01-05, Jan. 2016. [Online]. Available: https: //doi.org/10.15226/jdodt.2016.00148

[13] J.-Y. Chang, W.-C. Chen, T.-K. Huang, J.-C. Wang, P.-S. Fu, J.-H. Chen, and C.-C. Hung, "Evaluation of the accuracy and limitations of three tooth-color measuring machines," Journal of Dental Sciences, vol. 10, no. 1, pp. 16-20, Mar. 2015. doi: https://dx.doi.org/10.1016/j.jds.2013.04.004

[14] M. H. Kalantari, S. A. Ghoraishian, and M. Mohaghegh, "Evaluation of accuracy of shade selection using two spectrophotometer systems: Vita Easyshade and Degudent Shadepilot," European Journal of Dentistry, vol. 11, no. 02, pp. 196-200, Apr. 2017. doi: https://dx.doi.org/10.4103/ejd.ejd_195_16

[15] S. D. Kim, Y. Koo, and Y. Yun, "A smartphone-based automatic measurement method for colorimetric $\mathrm{pH}$ detection using a color adaptation algorithm," Sensors, vol. 17, no. 7, p. 1604, Jul 2017. doi: http://dx.doi.org/10.3390/s17071604

[16] M. K. Hasan, M. Haque, N. Sakib, R. Love, and S. I. Ahamed, "Smartphone-based human hemoglobin level measurement analyzing pixel intensity of a fingertip video on different color spaces," Smart Health, vol. 5-6, pp. 26-39, Jan. 2018. doi: https://doi.org/10.1016/j.smhl.2017.11.003

[17] Waldau Webdesign, "Lux light meter," Google Play Store: https:// play.google.com/store/apps/details?id=de.waldau_webdesign.lightmeter, 2019, accessed 22 May 2021.

[18] Loomatix, "Color grab," Google Play Store: https://play.google.com/ store/apps/details?id=com.loomatix.colorgrab, 2019, accessed 22 May 2021.

[19] A. R. Smith, "Color gamut transform pairs," in Proceedings of the 5th Annual Conference on Computer Graphics and Interactive Techniques, ser. SIGGRAPH '78. New York, NY, USA: Association for Computing Machinery, 1978. doi: https://dx.doi.org/10.1145/800248.807361. ISBN 9781450379083 p. $12-19$.

[20] C. Spearman, "The proof and measurement of association between two things," The American Journal of Psychology, vol. 15, no. 1, p. 72 Jan. 1904. [Online]. Available: https://doi.org/10.2307/1412159

[21] W. H. Kruskal and W. A. Wallis, "Use of ranks in one-criterion variance analysis," Journal of the American Statistical Association, vol. 47, no. 260, pp. 583-621, Dec. 1952. [Online]. Available: https://doi.org/10.1080/01621459.1952.10483441

[22] E. P. J. Tozer, Broadcast Engineer's Reference Book. Elsevier, 2004. ISBN 0-240-51908-6

[23] DIAL GmbH, "Luxmeter app versus measuring device: Are smartphones suitable for measuring illuminance?" Jun. 2006. [Online]. Available: https://www.dialux.com/en-GB/news-detail/luxmeter-app-versusmeasuring-device-are-smartphones-suitable-for-measuring-illuminance

[24] R. Melo, F. Carvalho, and D. Cerqueira, "Pitfalls of measuring illuminance with smartphones," in Occupational Safety and Hygiene VI. CRC Press, Mar. 2018, pp. 459-463. 